\title{
Low frequency events occurred during the sequence of aftershock activity of the 2003 Tokachi-Oki earthquake; a dynamic process of the tectonic erosion by subducted seamount
}

\author{
Kazushige Obara, Yoshikatsu Haryu, Yoshihiro Ito, and Katsuhiko Shiomi \\ National Research Institute for Earth Science and Disaster Prevention, 3-1 Tenno-dai, Tsukuba, Ibaraki 305-0006, Japan
}

(Received November 30, 2003; Revised February 16, 2004; Accepted February 16, 2004)

\begin{abstract}
During the sequence of aftershock activity of the 2003 Tokachi-Oki earthquake, anomalous events predominant in low-frequency components occurred very close to a subducted seamount around the junction between the Kuril Trench and the Japan Trench. The low-frequency wave train in the coda part reflects the strong excitation of surface waves and the source depth is considered to be very shallow. The focal mechanism of the low-frequency event is a type of the reverse fault. Considering with the source depth and the mechanism, the low-frequency event might have occurred on the plate boundary as a dynamic process of the tectonic erosion by the subducted seamount.

Key words: Low-frequency earthquake, 2003 Tokachi-Oki earthquake, subduction zone, tectonic erosion, seamount, plate boundary..
\end{abstract}

\section{Introduction}

The 2003 Tokachi-Oki earthquake with Mw 7.9 which occurred at 4:50 am (JST) on September 26, 2003 is the first M8-class interplate earthquake after the NIED (National Institute for Earth Science and Disaster Prevention) seismograph networks, Hi-net, F-net, K-NET, and KiK-net have been established with dense and homogeneous distribution over Japanese islands. These waveform data with wide dynamic ranges were quickly available through the internet and provided many opportunities to seismologists and others for various research works of the earthquake. Just after the occurrence of the main shock, a special page including the latest aftershock seismicity, moment tensor solutions of major earthquakes, distribution of strong motions and other information appeared on the NIED web-site (NIED Hi-net, 2003). According to the development of the nation-wide high-sensitivity seismograph network, the detection capability for microearthquakes and accuracy in the hypocentral determination has been improved. Figure 1 shows the distribution of the main shock and aftershocks relocated by NIED Hi-net adding the data of JAMSTEC (Japan Marine Science and Technology Center), Hokkaido University and JMA (Japan Meteorological Agency) with a homogeneous method using fixed stations around the aftershock area. The aftershocks are distributed in a rectangle area with a length of $150 \mathrm{~km}$ along the strike and $100 \mathrm{~km}$ in the dip direction. The northeast edge of the aftershock area is bounded by the Kushiro Canyon. The cross sectional view of hypocenter distribution indicates the inclined seismicity to the northwest direction corresponding to the dipping plate boundary (Earthquake Research Committee, 2003) based on the Kat-

Copy right(c) The Society of Geomagnetism and Earth, Planetary and Space Science (SGEPSS); The Seismological Society of Japan; The Volcanological Society of Japan; The Geodetic Society of Japan; The Japanese Society for Planetary Sciences; TERRAPUB. sumata et al. (2004) and other models. On the fault plane of the main shock, the distribution of aftershocks seems to be compensative with the co-seismic slip distribution derived from the source process inversion (Honda et al., 2004; Koketsu et al., 2004; Yagi, 2004; Yamanaka and Kikuchi, 2003), that is, aftershocks mainly occur in the small slip area (Ito et al., 2004). Aftershocks are distributed not only on the plate boundary but also with some offsets from the plane and focal mechanisms of these earthquakes are slightly different from that of the main shock based on the moment tensor analysis (Ito et al., 2004). After the main shock, inland shallow seismicity became very active in some parts in Hokkaido (JMA, 2004). These shallow events are considered to be triggered due to the occurrence of the M8-class main event. On the other hand, anomalous low-frequency (LF) earthquakes occurred on September 29, 2003, three days after the occurrence of the mainshock at between the aftershock area and the Kuril Trench during the sequence of the aftershock activity. This area is considered as a stable sliding aseismic zone. Therefore, the occurrence of LF events might indicate the stress redistribution due to the main shock and characteristics of the LF event might reflect the coupling status in this area. It might be important in order to understand the subduction process around the trench axis. From this point of view, the LF event was investigated and the mechanism of the LF event was discussed.

\section{Characteristics of Low-frequency Events: Lo- cation, Focal Mechanism and Seismogram}

Two low-frequency events (LF1 and LF2) occurred on September 29, 2003 with a time interval of 10 minutes during the active period of aftershock sequence (Fig. 1). Epicenters of the LF events determined by NIED Hi-net routine analysis are located outside of the aftershock area and close to the junction between the Kuril Trench and the Japan Trench as 

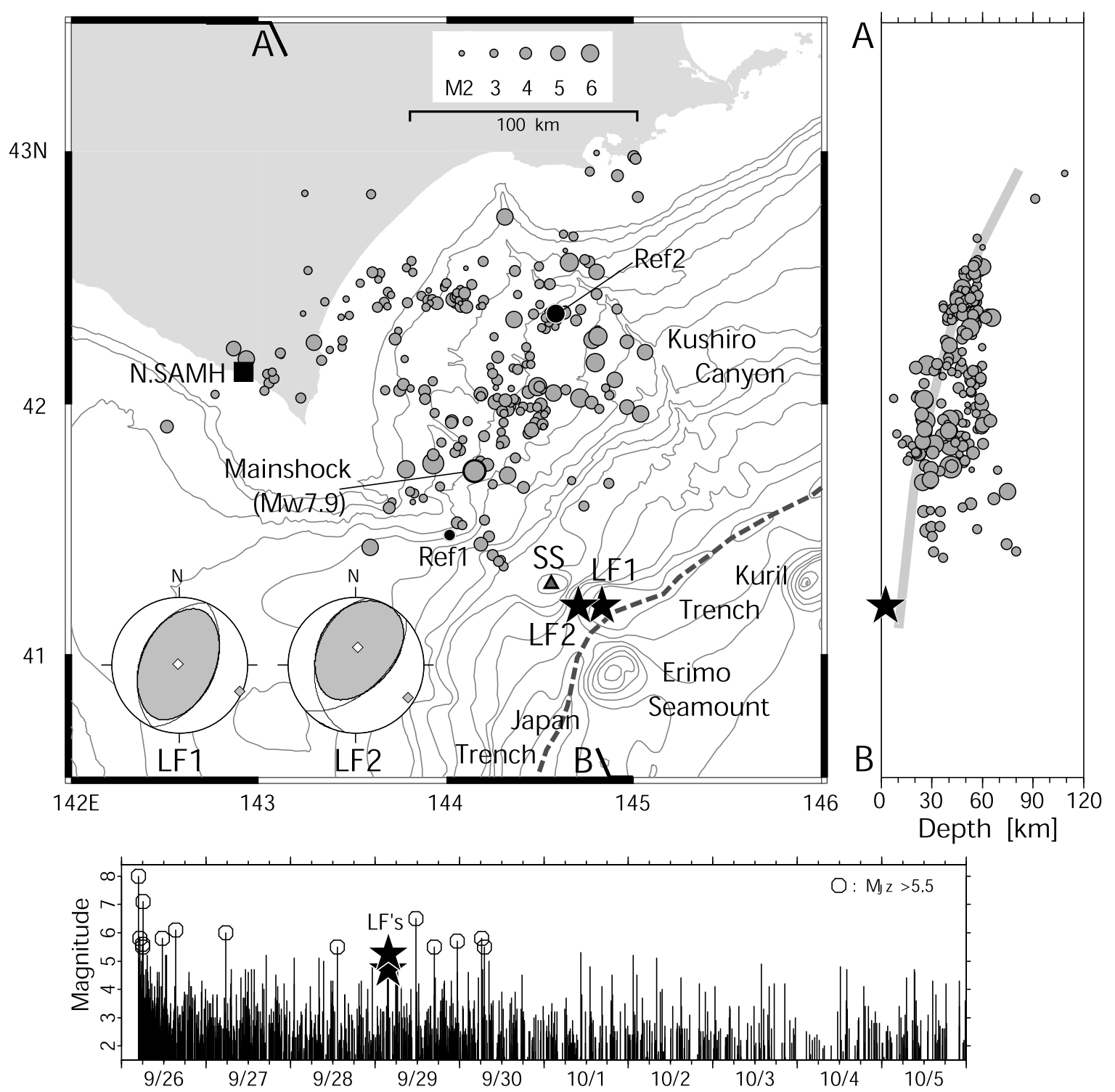

Fig. 1. (top) Hypocentral distribution of the main shock and aftershocks of the 2003 Tokachi-Oki earthquake and low-frequency (LF) earthquakes. Solid stars labeled LF1 and LF2 indicate the hypocentral location of LF events occurred at 3:37 am and 3:46 am, respectively. Aftershocks for the period of one month from the occurrence of the main shock are relocated by a homogeneous method with the fixed stations using stations of NIED Hi-net, JAMSTEC, Hokkaido University and JMA around the aftershock area. Well determined hypocenters with the horizontal error of less than 2 km and the vertical error less than $4 \mathrm{~km}$ are plotted on the bathymetric topography map. Focal mechanisms of the LF events estimated by the moment tensor inversion analysis are shown in the lower left corner. Solid circles labeled with Ref1 and Ref2 are the normal aftershocks whose seismograms are shown in Fig. 3 and Fig. 4 as references compared with the LF events. The solid square symbol is the location of the station N.SAMH where observed seismograms are plotted in the Fig. 2 and Fig. 3. The triangle symbol labeled with SS indicates the swell produced by a subducted seamount in the inner trench slope. The dashed line indicates the axis of the Kuril Trench and the Japan Trench. Along the profile of AB, the cross sectional view of aftershocks is shown in the right side. Gray bold line is the plate boundary along the AB profile proposed by Earthquake Research Committee (2003). (Bottom) Time sequence of aftershock activity for 2003 Tokachi-Oki earthquake and LF earthquakes. Earthquakes listed in JMA catalog located in the rectangle area shown in top panel are plotted with the time duration of ten days. Circles indicate earthquakes, of which the magnitude is greater than 5.5. LF events are indicated by star symbols.

shown in Fig. 1. Comparing with the bathymetric topography map, the LF events occurred at between the Erimo Seamount and a swell, indicated by a triangle symbol labeled with SS in Fig. 1, produced by a subducted seamount (Yamazaki and Okamura, 1989). Detailed parameters are listed in Table 1. Not only the two LF events but also some small LF events could be detected, however it is very difficult to distinguish them from the normal aftershock events.

Moment tensor solutions of the LF events estimated by NIED F-net broadband seismograph network are shown in
Fig. 1 and Table 1. The estimated depth is $5 \mathrm{~km}$ and the focal mechanism is a type of the reverse fault. The dip angle is about 30-40 degrees, which is slightly wide angle compared with the main shock and aftershocks indicated by Ito et al. (2004). The obtained depth of $5 \mathrm{~km}$ is the shallowest grid in this analysis; therefore the depth of the LF events is considered to be very shallow.

The seismogram of the LF event is characterized by lowfrequency components compared with that of normal aftershock events. Figure 2 shows a continuous recording chart of 
Table 1. Source parameters of low-frequency earthquakes. (a) NIED Hi-net analysis. (b) NIED F-net MT solutions. (a)

\begin{tabular}{cccccc}
\hline & origin time & Latitude & Longitude & Depth & Magnitude \\
\hline LF1 & $2003 / 09 / 2903: 3652.8 \mathrm{~s}$ & $41.192 \mathrm{~N}$ & $144.843 \mathrm{E}$ & $39 \mathrm{~km}$ & M3.6 \\
LF2 & $2003 / 09 / 2903: 4602.0 \mathrm{~s}$ & $41.192 \mathrm{~N}$ & $144.705 \mathrm{E}$ & $41 \mathrm{~km}$ & M4.1 \\
\hline
\end{tabular}

(b)

\begin{tabular}{cccccccc}
\hline & Mw & Mo & Centroid depth & Strike & Rake & Dip & Variance reduction \\
\hline LF1 & 4.7 & $1.27 \mathrm{e}+23$ & $5 \mathrm{~km}$ & $24 / 203$ & $91 / 89$ & $47 / 43$ & 50.1 \\
LF2 & 5.2 & $6.39 \mathrm{e}+23$ & $5 \mathrm{~km}$ & $48 / 189$ & $114 / 58$ & $57 / 40$ & 55.7 \\
\hline
\end{tabular}

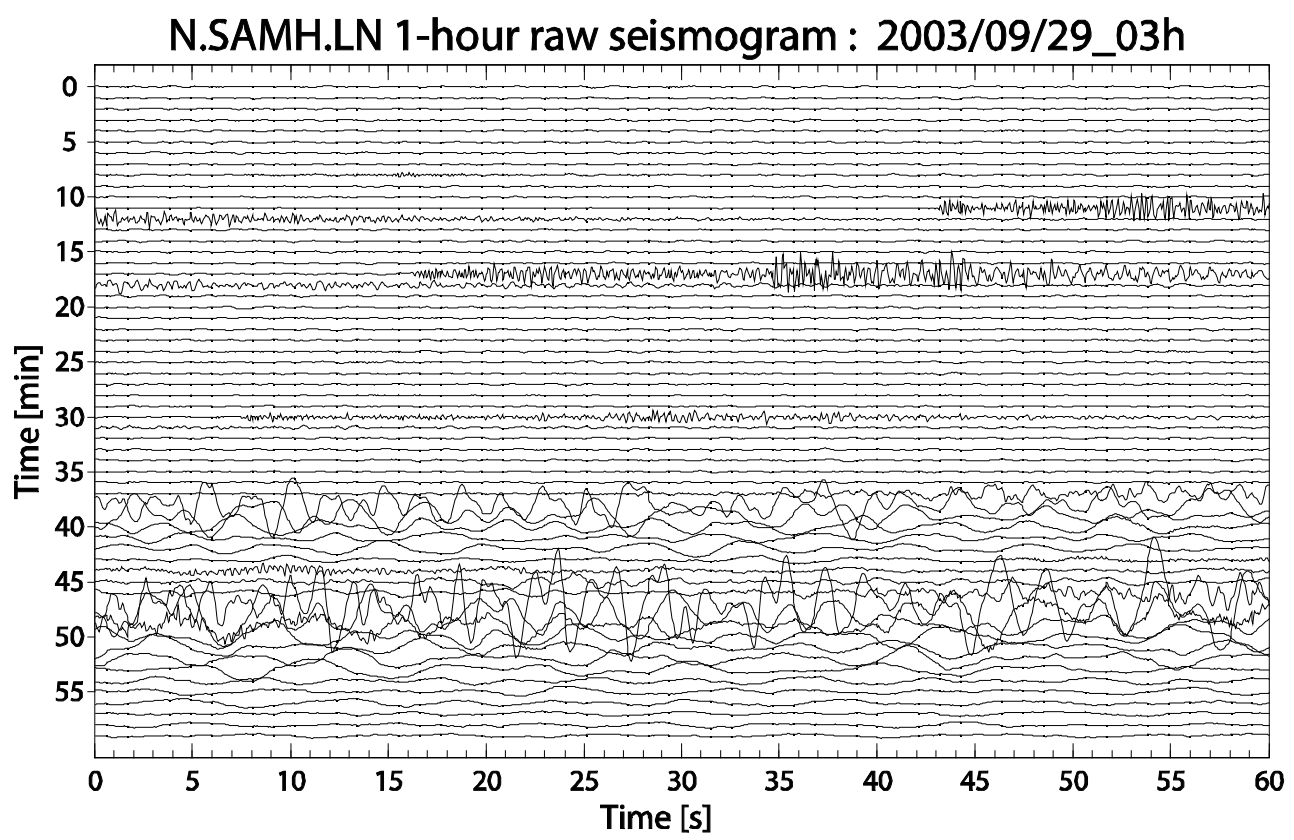

Fig. 2. One-hour continuous recording chart of the raw seismogram observed by the horizontal component of the high-sensitivity accelerometer at the NIED Hi-net station N.SAMH in 3 o'clock on September 29, 2003. LF events appear from 3:37 and 3:46. Relatively short-period seismograms appeared 3:11, 3:17 and 3:30 are normal aftershocks.

the high sensitivity accelerometer observed at N.SAMH with the time period of one hour. There are a few seismograms of normal aftershock events in the first half of the one hour. Around 3:37 am and 3:46 am, very long period wavetrains of LF events like a teleseismic waveform were appeared. Figure 3 shows the difference in the seismogram and its power spectral density between the LF2 and a normal aftershock event with almost the same magnitude and the location as a reference. The epicenter of the reference event is also plotted in Fig. 1. Traces are corrected for their instrumental response. The seismogram of the LF event is characterized by the low-frequency $P$ wave with small amplitude and the long lasting low-frequency coda wave, which is predominant in the frequency of lower than $1 \mathrm{~Hz}$. Waveforms of the two LF events are very similar but they are not defined as an earthquake family because of slight difference. Figure 4 shows the propagation of wave trains in the low-frequency coda portion of the LF event and a normal earthquake as a reference. Plotted traces were operated by the low-pass filter which has the corner frequency of $0.05 \mathrm{~Hz}$. The low-frequency wave trains with the propagation velocity of about $3.2 \mathrm{~km} / \mathrm{s}$ are considered as surface waves and the duration of the surface wave of the LF event is longer than that of the reference normal major aftershock. The strong excitation of the surface wave indicates that the source depth is very shallow.

\section{Discussions}

Aftershocks of the 2003 Tokachi-Oki earthquake mainly occurred on the subducting plate boundary and the distribution of aftershocks is regarded as the seismogenic zone. The location of the updip limit of the seismogenic zone, which is usually locked, is very important to evaluate the strong motion and tsunami disaster when the mega-thrust earthquake occurs. The seaward updip portion of the seismogenic zone is considered as the stable sliding aseismic area and the LF events occurred in this area. The geological structure and tectonics between the locked seismogenic zone and the trench axis is different in each convergent trench margin. At the Nankai Trough there exists the sedimentary accretionary prism above the decollement stable sliding zone and many reverse fault system including the out-of-sequence thrust are developed in the accretionary prism (i.e. Kuramoto et al., 2000). On the other hand, there is no accretion in the western Kuril and Japan Trenches and the tectonic erosion 
a)

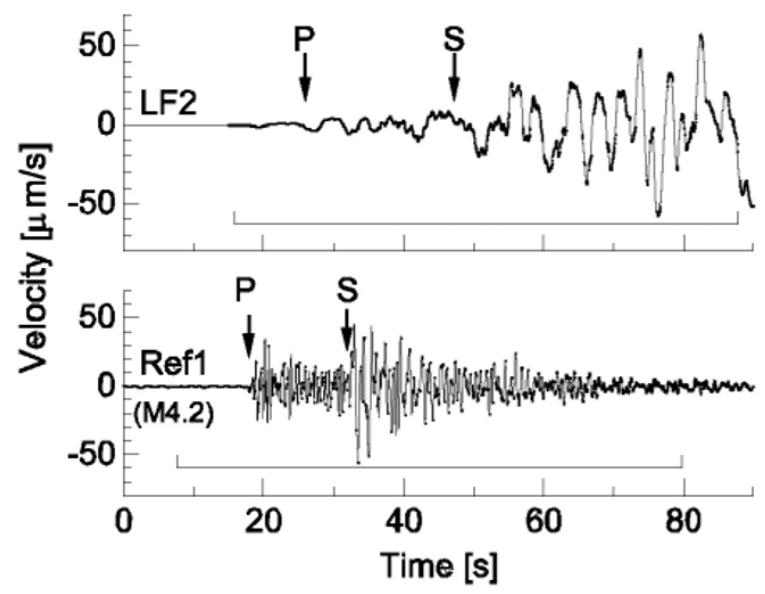

b)

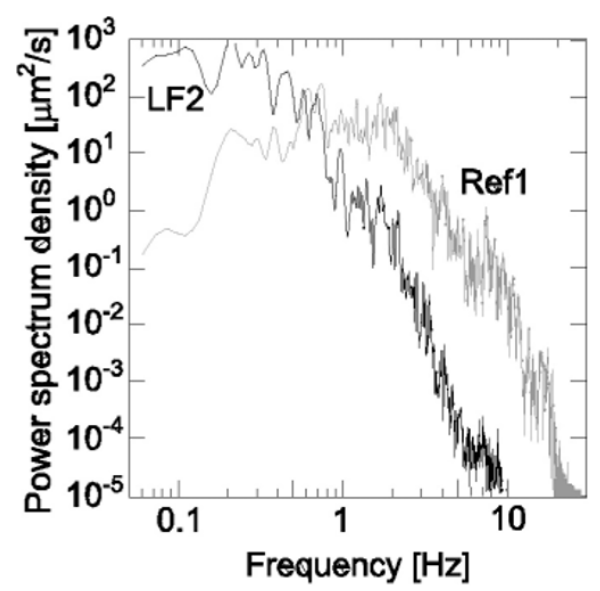

Fig. 3. (a) Waveforms of the LF2 and a reference event (Ref1) observed by the vertical component of the short-period velocity seismometer at the station N.SAMH. The reference event is located close to the LF events and the magnitude (M4.2) determined by NIED Hi-net routine analysis is almost the same as that of LF2. Traces with correction for the instrumental response are plotted. The horizontal axis is the lapse time from the origin time of these events. The vertical axis is the velocity amplitude. The horizontal bar indicates the time window for the calculation of the power spectrum density as shown in (b). (b) Power spectrum density of the seismograms of LF2 and Ref1 calculated for the time window shown in (a).
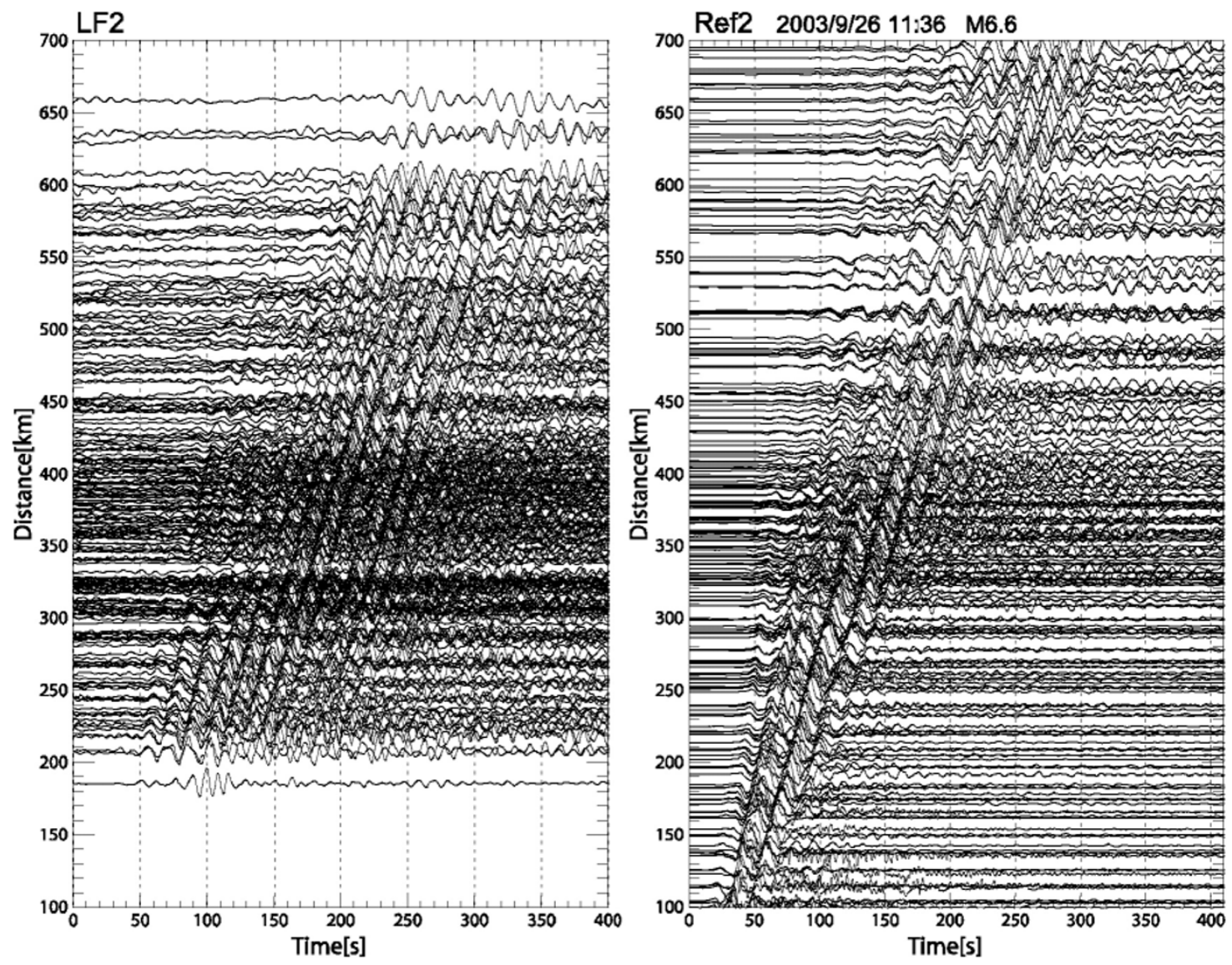

Fig. 4. Paste up traces of the LF2 and Ref2 events observed in NIED Hi-net stations. Vertical component seismograms of the velocity seismometer are processed by the low-pass filter with the corner frequency of $0.05 \mathrm{~Hz}$ and normalized by their maximum amplitude in the time period. The horizontal axis is the lapse time from the origin time of each event.

of the trench margin occurs along the underside of the upper plate and at the base of the continental slope (Von Huene and Culotta, 1989). Around the junction between the Japan Trench and the Kuril Trench, the detailed bathymetric surveys were carried out by the seabeam method (Kaiko I Re- search Group, 1986). Yamazaki and Okamura (1989) proposed the existence of an already subducted seamount under the inner trench slope northwest of the Erimo Seamount on the basis of magnetic anomalies and the anomalous tomography. According to their model, the subducting seamount 
pushes inner trench slope material forward and upward and produces a swell in front of it. Behind the seamount a depression remains. As a result, the subducting seamount should be located between a pair of a swell and a depression. Comparing the horizontal location of the LF events and the bathymetric map in Fig. 1, the LF events seems to be located between the swell and the depression plain besides the trench axis. Therefore, epicenters of the LF events correspond to the proposed location of the subducted seamount very well. The seamount subduction causes the uplift of the inner trench slope and the normal faulting system due to horizontal extension. At the underside of the upper plate, the basis erosion forms the decollement enriched with fluid. The decoupled zone is considered as the path of fluid dehydrated from the underthrusting oceanic crust and sediments because of the existence of strong reflector (Moore et al., 1998). Unconsolidated or semiconsolidated sediments and hydrous smectite clays exist along the decollement and transformation of smectite to illite as a function of temperature controls the updip limit of the seismogenic zone (Hyndman et al., 1997). Near the trench axis, the decollement is considered as the stable sliding aseismic zone. However, the subducted seamount may contact with the underside of the upper plate with relatively strong friction and act as an asperity which has potential of faulting with radiation of seismic waves. Due to the sudden stress accumulation by the occurrence of the mainshock, the stress change might not be released unealistically and a relatively fast slip might occur on the decollement at the top of the subducted seamount. Considering the tectonics in this area, the reverse fault type mechanism of the LF event supports the rupture on the decollement. The low-frequency contents in the body wave indicate the low rupture velocity, which suggests that the interface condition of the rupture fault is different from that of normal earthquakes. Hydrous materials that exist on the decollement like as gauge may control the rupture process. Therefore the LF event might be triggered by the stress redistribution by the M8-class event as a dynamic process of the tectonic erosion on the decollement due to the existence of the subducted seamount.

\section{Conclusions}

Anomalous low-frequency events occurred during the sequence of aftershock activity of the 2003 Tokachi-Oki earthquake. The horizontal location of the LF events corresponds to a subducted seamount around the junction between the Kuril Trench and the Japan Trench. The focal mechanism of the event is a type of the reverse fault. The depth of the event is estimated to be very shallow based on the moment tensor analysis and the strong excitation of surface waves. Estimated mechanism and the depth suggest that the event might occur on the plate boundary near the trench axis as a dynamic process of the tectonic erosion by the subducted seamount at the base of the upper plate.
Acknowledgments. The data of JAMSTEC, Hokkaido University, JMA, and NIED Hi-net were used in the hypocentral determination of aftershocks. GMT (Wessel and Smith, 1991) was used to make figures. Comments from reviewers were very useful for improvement of the manuscript.

\section{References}

Earthquake Research Committee, Long-term evaluation of earthquakes along the Kuril Trench (March 142003 corrected on August 14 2003), http://www.jishin.go.jp/main/chousa/03mar_chishima/index.htm, The Headquarters for Earthquake Research Promotion, Tokyo, 2003.

Honda, R., S. Aoi, N. Morikawa, H. Sekiguchi, T. Kunugi, and H. Fujuwara, Ground motion and rupture process of the Tokachi-Oki Earthquake obtained from strong motion data of K-NET and KiK-net, Earth Planets Space, 56, this issue, 317-322, 2004.

Hyndman, R. D., M. Yamano, and D. A. Oleskevich, The seismogenic zone of subduction thrust faults, The Island Arc, 6, 244-260, 1997.

Ito, Y., H. Matsubayashi, H. Kimura, T. Matsumoto, Y. Asano, and S. Sekiguchi, Spatial distribution for moment tensor solutions of the 2003 Tokachi-oki earthquake $\left(\mathrm{M}_{\mathrm{JMA}}=8.0\right)$ and aftershocks, Earth Planets Space, 56, this issue, 301-306, 2004.

JMA, Sketch of the Tokachi-Oki earthquake in 2003, Reports of the Coordinating Committee for Earthquake Prediction, 71, 84-95, 2004.

KAIKO I Research Group, Topography and structure of trenches around Japan —Data atlas of France-Japanese KAIKO project, Phase I., University of Tokyo Press, Tokyo, 305 pp., 1986.

Katsumata, K., N. Wada, and M. Kasahara, Newly imaged shape of the deep seismic zone within the subducting Pacific plate beneath the Hokkaido corner, Japan-Kurile arc-arc junction, J. Geophys. Res., 2004 (in press).

Koketsu, K., K. Hikima, S. Miyazaki, and S. Ide, Joint inversion of strong motion and geodetic data for the source process of the 2003 Tokachioki, Hokkaido, earthquake, Earth Planets Space, 56, this issue, 329-334, 2004.

Kuramoto, S., A. Taira, N. L. Bangs, T. H. Shipley, G. F. Moore, and EW9907, 08 Scientific Parites, Seismogenic zone in the Nankai accretionary wedge: General summary of Japan-U.S. collaborative 3-D seismic investigation, J. Geography, 109, 531-539, 2000 (in Japanese with English abstract).

Moore, J. C., N. B. Klaus, B. Bekins, C. J. Bucker, W. Bruckmann, S. N. Erickson, O. Hansen, T. Horton, P. Ireland, C. O. Major, G. F. Moore, S. Peacok, S. Saito, E. J. Screaton, J. W. Shimeld, P. H. Stauffer, T. Taymaz, P. A. Teas, and T. Tokunaga, Consolidation patterns during initiation and evolution of plate-boundary decollement zone: Northern Barbados accretionary prism, Geology, 26, 811-814, 1998.

NIED Hi-net, Special page for the 2003 Tokachi-Oki earthquake, http://www.hinet.bosai.go.jp/topics/tokachi0309/, 2003.

Von Huene, R. and R. Culotta, Tectonic erosion at the front of the Japan Trench convergent margin, Tectonophysics, 160, 75-90, 1989.

Wessel, P. and W. H. F. Smith, Free software helps map and display data, Eos Trans. AGU, 72, 445-446, 1991.

Yagi, Y., Source rupture process of the Tokachi-oki earthquake of September 26 2003, determined by joint inversion of teleseismic body wave and strong motion data, Earth Planets Space, 56, this issue, 311-316, 2004.

Yamanaka, Y. and M. Kikuchi, Source process of the recurrent Tokachioki earthquake on September 26, 2003, inferred from teleseismic body waves, Earth Planets Space, 55, e21-e24, 2003.

Yamazaki, T. and Y. Okamura, Subducting seamounts and deformation of overriding forearc wedges around Japan, Tectonophysics, 160, 207-229, 1989.

K. Obara (e-mail: obara@bosai.go.jp), Y. Haryu, Y. Ito, and K. Shiomi 